Military Technical College

Kobry El-Kobbah, Cairo, Egypt

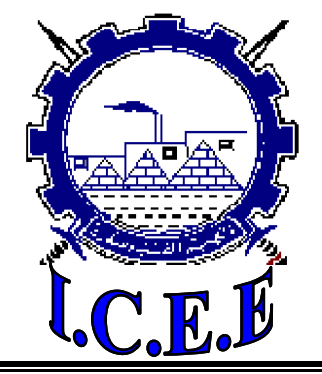

CE-3 $5^{\text {th }}$ International Conference on

Chemical \& Environmental Engineering

\title{
ABOUT THE EFFECTIVENESS AND PERFORMANCE OF A COMPACT CIRCULATING FLUIDIZED BED REACTOR IN CHEMICAL ENGINEERING PROCESSING
}

\author{
Mohammad Z. Abdel Wahhab*
}

\begin{abstract}
In may 2002, the author presented ( in the first CEE conference at MTC, Egypt, a new design for a compact circulating fluidized bed (CCFB), to be used for incineration of solid wastes for pollution prevention and control of the environment. The present paper tries to evaluate the effectiveness and performance of such a design in another field of chemical engineering processing; this is the drying of solids or humidification of air. Results proved an acceptable performance for solids drying and for the use of solids as desiccants as well as humidification and dehumidification of gases. The results may be extended to the use of solids as adsorbents with acceptable performances.
\end{abstract}

\section{Keywords}

Fluidization, Circulation, Drying, Desiccants, Humidification.

\footnotetext{
${ }^{*}$ Chemical Engineering, Fac. Of Engineering, Minia Univ., Minia, Egypt.
} 


\section{INTRODUCTION}

By entering the field of catalytic cracking in the year 1942, fluidization hit the industrial scene moving its application into many other areas. Its huge success and its spectacular flops spurred research efforts so as to have now thousands of reported studies on the subject and its applications.

As for solid-gas fluidization systems, fluidization is the operation by which fine solids are transformed into a fluid like state through contact with the gas. This method of contacting has a number of unusual characteristics for which efforts had been concerned to take the advantage of this behaviour and put it to good use. According to the dynamic behaviour of solids, fluidized beds can be classified to normal fluidized beds, teeter beds and spouted beds. Nevertheless, according to the mode of solids movements, dense phase fluidized beds may be of the batch type, circulation type or the "one pass for solids" type. This last type of modes is used industrially for drying of solids and for ores particle growth by deposition as physical operations, while the chemical reactors for that mode are used for roasting of sulphide ores, calcination of lime stone, gasification of coal, activation of charcoal, reduction of ion ore and for the production of cement. Circulating fluidized beds proved to be useful tools for the same operations and processes industrially carried out by the " one pass for solids " fluidized beds ; and in addition they are used for the adsorption of water vapor by silica gel, the fluid catalytic cracking, reforming of naphtha, fluid coking, thermal cracking of hydrocarbons and for the vaporization of oil-shales [1] .

Different forms of gas-solid contacting and flow occur in various sections of any circulating system; this is necessary to achieve stable circulation. These forms may include pneumatic conveying, moving beds, fluidized solids transport, and nearly always one or more fluidized beds. The basic problem is then to decide what type of flow and what type of pressure are to be maintained in different sections of the circulating system; in addition how to control temperature dissipation through the long path of circulation [2].

The problem of maintaining fixed temperature all over the length of the circulation path remained a problem open to discussion, since the circulation of solids remained always outside temperature control, being - in nearly all designs- outside the main body of the fluidizing dense phase. Many designs tried to arrange all circulating lines in the horizontal and down flow sections as near as possible from the main fluidization body containing the upper- flow stream, but results showed modest advancements in energy conservation and stability [2].

The present investigation is a second step in the advancement of testing, the feasibility and effectiveness of a compact design previously tested in pollution control of the combustion operations getting polluting flue gases or polluting ashes [3]. This compact design contains the up-stream, horizontal stream and the down stream inside the main body of fluidization of he dense phase. The lean phase free board over the dense phase terminates in its upper section by separating cyclones to get entrained solids back to the dense phase, where the gas going out of the cyclone ( and of the reactor ) becomes then nearly free of solid entrainments .

\section{DESIGN FEATURES AND HYDRODYNAMICS TESTING:}

Figure 1, represents, schematically, a Perspex reactor erected for testing the hydrodynamics of solids circulation at ambient conditions. Sand of different particle sizes was chosen for testing the conditions accepted for the choice of solid batches. Using this reactor it was amenable to 
identify the quality of the bed fluidization so as to attain the best circulation conditions, to choose the best barrier height for continuity and ease of solid circulation and to test the best accepted distributer design for the process. Details of the design dimensions, solids sizes and batches, the fluidizing air velocities and the method of judging the quality of fluidization and circulation were discussed in a previously presented article [3].

Information about the important details of a metallic reactor especially designed for testing its performance and effectiveness for incineration of solid effluents from industries, hospitals and urban areas was also described in reference [3]. A schematic representation of its parts and connections is shown in Figure 2 for comparison. The modifications of the original design made to conform with the requirement of the present investigation are shown in Figure 3. These were made to test the feasibility of the new compact circulating bed design shown in Figure 2 for the humidification and de-humidification of solids, especially those dissicant solids frequently used in chemical engineering processings.

To ensure the advantageous character of the present design rather than normal designs of the circulating fluidized beds, the installation shown in Figure 4 was used for comparison with the present modified design.

\section{CHOICE OF MATERIALS (DISICCANTS)}

Air is used as the fluidizing and humidifying (or de-humidifying) gas. It was used in its normal atmospheric conditions, being only filtered for cleaning from particulates and then humidified or dehumidified according to the requirement of the testing run. Air was heated in the heating chamber connected to the original design (or, heated externally using chosen electric tube furnace in case of low heating conditions), if temperature was to be higher than ambient.

In order to widen the scope of the present testing, the chosen solid materials were constricted to those solids normally used as desiccants in laboratories and in small scale operations, and additionally, to those solids used as adsorbents. This latter choice may be of benefit in regeneration of solid adsorbents and / or solid catalysts normally used on an industrial scale.

The present investigation, restricted its testing action on four widely used solids normally used for both industrial and laboratory works. These are : silica gel, activated alumina, drierite and anhydrone.

Silica gel, is a highly porous type of silica prepared by the action of hydrochloric acid $(10 \%)$ at $50<^{\circ} \mathrm{C}$ on sodium silicate [4]. Its capillary pores occupy $50 \%$ of its specific volume; the average pore diameter is about $4 \times 10^{-7} \mathrm{~cm}$, which is nearly ten times that of the water vapour molecule. It is chemically, physically and thermally stable and has the advantage of undergoing an unlimited number of reactivations [5].

Activated alumina is generally prepared from aluminium oxide trihydrate. It is a granular porous adsorbent of properties very near to those of silica gel. Activation is generally carried out by subjection to hot air or any gas chemically inert to alumina at the temperature of activation; generally nitrogen is used, if air is not to be considered.

Drierite, anhydrous calcium sulphate, is generally prepared from calcium sulphate dihydrate (gypsum), by drying, crushing, sizing and heating at about $230^{\circ} \mathrm{C}$ for two hours where a 
granular porous form of calcium sulphate is formed [5]. This product is characterized by having sufficient mechanical strength to resist impact and erosion action of the fluidized circulating particles. This latter statement was proved by preliminary circulating runs at the highest air velocities used during the investigation runs. Preliminary experiments proved also that drierite can catch up to $15 \%$ of its weight of water vapour due to its porous structure, in comparison with about $7 \%$ only for the original gypsum from which it as prepared.

Anhydrone is the scientific (and industrial) nomination given to the chemical compound known as magnesium perchlorate. It is an adsorbent normally used for removing traces of humidity included in sensitive solids (especially in the pharmaceutical industry) [5]. It has a rapid rate of adsorption up till about $230^{\circ} \mathrm{C}$ where it can be used with high efficiency. Thermogravimetric analysis showed three hydrates, the first of which does not lose water until $135^{\circ} \mathrm{C}$, thereby permitting its use at temperatures higher than most well known desiccants. It has the disadvantages of higher cost and problematic techniques of regeneration, yet it has its own industrial uses which is one of its characteristics over other desiccants. The hexa-hydrate represents saturation after adsorption of $48.8 \%$ of its dry weight of water, which is a high capacity, if compared with the di-or the tri-hydrates of the perchlorate, or even if compared with any other desiccant for the same objective [5].

The sizes of particles were chosen to be about $60 \mu \mathrm{m}$ for the B-type particles and about 600 $\mu \mathrm{m}$ for the D-type particles [6,7]. The surface area for these particles ranged from $383 \mathrm{~m}^{2} / \mathrm{m}^{3}$ for coarse particles $(600 \mu \mathrm{m})$ up to $3733 \mathrm{~m}^{2} / \mathrm{m}^{3}$ for fine ones $(60 \mu \mathrm{m})$. Between these two figures different particles surface areas were determined experimentally by liquid Nitrogen technique for different materials examined. Batches prepared for experimental tests were sized from the same material so as to have conformity and consistency in the circulating barches. Wen and $\mathrm{Yu}$, proposed a ratio of coarse to fine particles in a bed to be less than $\sqrt{2}$ for better fluidization [8], this was not the case for circulating beds as proved experimentally.

\section{Experimental}

Figure 4 represents the original connections for the apparatus and accessories required for the humidification or dehumidification of solids in circulating fluidized beds of the normally used type. The fluidizing reactor contains only the up-stream, while a system of separating cyclones outside the reactor body constitutes the horizontal stream; the down stream is an inclined connection between the under-streams of the cyclones, returning back to the main reactor. Connections for sampling of solids and air are included in-between. The inlet air to the reactor may be either humidified by passing through a series of water vessels, or being passed through connected calcium chloride columns for dehumidification. Inlet air samples may be taken from the line entering the reactor.

In order to change operation to the new designed reactor, it simply consists in changing the reactor and its outlet connections (cyclones and down stream line) and replacing by the new design shown in Figure 3.

According to the mode of operation required, whether humidification or dehumidification of solids, these solids are prepared, either by being fluidized by a stream of dry hot air for two hours or by a stream of saturated wet air for the same period. The solids obtained in both cases are re-weighed to register the change of its original weight, either positively or negatively. To this aim 10 grams of the charge were weighed before and after treatment by 
air, to obtain the increase or decrease of moisture per gram. Humidification or dehumidification of solids was carried out in a Perspex fluidized bed reactor.

Solids weight for a batch in the reactor changed according to the specific gravity of the batch, which varied from one desiccant to another. Wide-range sizes were used for better quality of fluidization and for circulation continuity. Preliminary experiments were designed to decide the charge sizes and masses and to choose the best height of static charges in the column. These experiments also were a mean to decide the least size of solid fines used such that the amount of fines entrained in the exit air stream from the new designed reactor (which is actually the exit from its internal cyclone) becomes negligible and thus can not affect the quantity of the charge or the quality of fluidization [9]. For the same reason, solid samples taken all over the period of a run were re-admitted to the reactor by a designed mechanism (16) using a hot air line from the serpentine carrying the fluidizing air to the reactor .

The prepared mixes of solids are fed to the funnel shaped inlet containing a verticallymounted screw conveyor manually-operated via a gear box connection. The narrow tube containing the conveyor ends by a larger cross-section ending with a one-way gate valve permitting the outlet of solids to the riser section (I) of the reactor, where the solids accumulate on the distributer (1), through which a slow stream of air may flow, just for distributing the solids evenly on the hole riser cross-section. The required height of solids in the riser was found to be 3.6 times the cross-section width, which is about two-third the width of the down flow section (II). The air flow inside the reactor was measured by a pitot-tube (15), mounted vertically paralled to the air-flow direction; this is connected to a U-tube manometer for measuring the pressure drop, as a water head. The velocity of air (V) was calculated using equation (1) [10]:

$$
\text { Vair }=\mathrm{Cp} \sqrt{2 g h}
$$

Where

Vair $=$ air velocity $\quad \mathrm{cm} / \mathrm{s}$

$\mathrm{Cp}=$ coefficient of the Pitot-tube, which was determined experimentally and found to be equal to 0.976 for abient temperature, and up to $40^{\circ} \mathrm{C}$ air temperature.

$\mathrm{g}=$ acceleration of gravity $\mathrm{cm} / \mathrm{s}^{2}$, and

$\mathrm{h}=$ head as measured by the manometer connected to the Pitot-tube, $\mathrm{cm}$

Air velocities between $1 \mathrm{~m} / \mathrm{s}$ up to $6 \mathrm{~m} / \mathrm{s}$ were used for testing experiments, depending on the mean particle size of batches as calculated by screen analysis using the following relation: [11(a)]

$$
\mathrm{Dp}=1 / \sum_{i=1}^{n}\left(\mathrm{x}_{\mathrm{i}} / \mathrm{D}_{\mathrm{pi}}\right)
$$

Where $x_{i}$ is the mass fraction of species (i) of diameter $D_{p i}$.

The exit stream going out of the cyclone ( and of the reactor ) flows to humidity and carryover fines measurements. The long leg of the cyclone embedded in the down-flow section 
returns back the particles separated to be within the down flow section, circulating again with the up-flow stream.

Temperature of the fluidizing air was controlled mainly by adjusting the flow rate within the fluidization and circulation requirements. The fuel -air ratio in the heating furnace can also be another controlling factor. Temperature of the bed was measured in the down-flow section (II) of the reactor using either glass thermometers or copper constantan thermocouples.

Temperature measuring elements (13), were isolated from the reactor charge, being put in a separated tube inserted in the down-flow section centrally and intermediate to its whole length. The closed tube is welded to the outer wall of the reactor.

Solid samples were taken through line (3), by arrangements of some on-off valves. Same line could be used for product exit at the end of a batch processing and or within the scope of a continnous operation through line (8).

Exit air samples were either tested for humidity measurement or for determining its contents of carry-over fines as entrainments. Humidity measurement was carried out by passing the exit air through two hot oil filters at $120^{\circ} \mathrm{C}$ in series to separate its solid possible contents, then through series of weighed calcium chloride-granules columns. The total humidity is known by difference in weight of the columns. Knowing the rate of air flow, and the time of columns passage, the air total volume could be concluded. The connection of the calcium chloride columns ensured the possibility of using one or more of these columns at a time for a certain time interval of the whole drying period of a run. This could be made by an arrangement of some on-off valves.

The height of the lean-phase space of the reactor (III), was calculated such that the elutriation rates of the solids used in the present investigation for sizes above 20 microns cannot effect the carry-over to the exit stream from the cyclone (4), In that respect, it was taken into consideration not to use fine particles less than 20 microns in the research batches for humidification studies.

\section{EXPERIMENTAL PROCEDURE}

The charge to an experiment ranged from 900 grams up to 1200 grams depending on the specific gravity of the coarse particles. The charge contained from $1 \%$ to $7 \%$ fines. Coarse and fine particles were thoroughly mixed in a small laboratory ball mill container from which all its ball contents were excluded, mixing continued for about 20 minutes at slow mixing speeds (10-20 rpm). Screen analysis testing showed no change in particle sizes or size distributions after the mixing period. Batch processing was the technique designed for this investigation studies.

Through the manually operated feeder (5), the feed mix was fed to the reactor in section (I), passing the hinged operating gate valve at its end; the charge fills nearly the space from the distributer (1) to the lower end of the feeding channel (7). Fluidizing air (9) is allowed to flow through the separatine (12) to be heated to the pre-adjusted temperature of the chamber (11) heated by a fuel air burner (if required). The initial air velocity was not to exceed the minimum fluidization velocity of the charge, which was well known through preliminary experiments. Air velocity was increased gradually within 20 seconds to the required air velocity for the experiment. Air velocities for circulation were about 10 times to 12 times the 
minimum fluidization velocities for batches; these velocities ranged from $1.3 \mathrm{~m} / \mathrm{s}$ to $3.6 \mathrm{~m} / \mathrm{s}$, as measured by the Pitot-tube assembly (15) mounted in the route of the riser fluidizing air (section I). The temperatures of the furnace chamber (11), that of the air going out of the serpentine (12) and the corresponding temperature of the charge settled on the distributer were comparatively assured by preliminary experiments, so as to fix the required temperature of the batch solids before circulation in relation to the air velocity required for the batch charge of solids.

The duration for an experiment was fixed at 40 minutes (the time period through which preliminary experiments showed stability of the particle size and particle size distribution of the bed charge) above which it was found to have gradual changes, though small, in the bed size distribution.

Temperatures of the dispersed phases in the riser and down-flow sections (I and II) were measured by temperature probes imbedded in sealed cavities in the reactor body (13). Solid samples were extracted from the sampling line (3); in case the samples were required to be returned back to the bed, a simple designed connection was welded in between an air flow line and an access to the base of the lean phase section (III); this is the element number (16) in Figure 3. Exit gases from the cyclone, out of the reactor, were directed either to humidity measurement, to carry-over fines tracing or to the atmosphere via a system of treatment of environmental friendship.

\section{HUMIDITY MEASUREMENTS}

Humidity was measured by difference in weight for both solid desiccants and exit air from the reactor. For solids, they were humidified using a Perspex reactor by the fluidized bed technique. This transparent reactor was $10 \mathrm{~cm}$ diameter, where solids were fluidized by humid air, saturated by passing through three successive water columns of slow flow rates, about the minimum fluidization velocity value of the charge. The time of humidification was about two hours. The difference in weight before and after the two hours period of fluidization gives the weight of moisture adhered to the charge particles.

Exit air from the cyclone in Figure 3, passes first through an oil-bath heated to about $120^{\circ} \mathrm{C}$, to catch its possible contents of solids without any possibility for condensation of its humidity, then through successive calcium chloride granules columns. The difference in weight of these columns registers the total humidity caught by the air stream from the solids in the reactor (Figure 3), through the whole period of the batch process.

\section{CARRY-OVER STUDIES OF FINES}

In the route of performance and effectiveness of the present design, it was important to test the elutriation possibilities of fines from the bed at different circulation conditions. For such a study, fines were used in sizes less than 100 microns in different percentages in the circulating batches. Separate experiments, specified by their consistency of batches and constant contents of solid humidity, were done. The exit air steam from the reactor was arranged so as to enable to catch samples of the exit stream by some on-off valve arrangements at different intervals of time.

Elutriated solid samples were caught by means of small (previously weighed) filter bags titely screwed to the mouth of the outlet T-pipe of the exit stream of air. The time of sampling can be deduced to be inversely proportional to the velocity of the fluidizing and circulating air 
velocity ; being of smaller values for higher air velocity values, and vice versa. The time of sampling ranged from 10 seconds up to 90 seconds for air velocities as high as $2 \mathrm{~m} / \mathrm{s}$, to a lower value of $0.5 \mathrm{~m} / \mathrm{s}$; a stop watch was a mean to manually adopting sampling times within a range of \pm 3 seconds.

\section{SAMPLING TECHNIQUE}

The internal circulation pressure inside the reactor was the factor affecting sampling, via an on-off valve. It was important that any single sample sivould not be more than $1 \%$ of the weight, and that the total number of samples should not exceed a number of ten samples; this was to ensure the stability of the bed[12]. Since the main objective of the present investigation is to test the feasibility and effectiveness of the designed reactor, results are not highly affected except by the homogeneity and continuity of the circulating conditions. In that sense, it could be important to return back samples extracted from the bed again to the circulating stream; this was carried out via a return system shown in Figure 3. Preliminary experiments showed that this return technique defects, were much lower than those defects happened due to losing the weight of ten samples from the bed, where the total vapour pressure of humidity content of solids inside the reactor combensates, to an acceptable extent, errors in humidity measurements.

\section{SOME USEFUL DEFINITIONS}

1- The humidity, H, mentioned in the results as the moisture content, M.C., in defined as the mass of vapour (water vapour) carried out by a unit mass of vapour-free gas (air). For solids it is the total water content mass per unit mass of solids [11(b)].

$$
\mathrm{H}=\frac{M_{A} \mathrm{P}_{A}}{M_{B}\left(1-\mathrm{P}_{A}\right)}
$$

Where, $\mathrm{P}_{\mathrm{A}}=$ Partial pressure of $\mathrm{A}$, atm.

- $\quad \mathrm{M}_{\mathrm{A}}, \mathrm{M}_{\mathrm{B}}=$ molecular weights of components A,B (gas phase)

- In the gas phase the vapour is the component A (water) and the fixed gas (air) is the component B.

2- The percentage relative humidity,

$$
\mathrm{H}_{\mathrm{R}}=\frac{\mathrm{P}_{a}}{\mathrm{P}_{S}} \times 100
$$

Where :

- $\mathrm{P}_{a}$ is the partial pressure of water vapour in air, atm.

- $\mathrm{P}_{s}$ is the saturation pressure of water vapour in air, atm.

3- The percentage humidity, $\mathrm{H}_{\mathrm{p}}$, is defined by eq. (5) as:

$$
\text { mass of water vapour per unit mass of dry air x } 100
$$

mass of water vapour per unit mass of saturated air

4- As a conclusion,

$$
\begin{array}{r}
H_{p}=\frac{\mathrm{P}_{a}\left(\mathrm{P}-\mathrm{P}_{S}\right)}{\mathrm{P}_{S}\left(\mathrm{P}-\mathrm{P}_{a}\right.} x 100 \\
\text { i.e. } H_{p}=H_{R}\left(\frac{\mathrm{P}-\mathrm{P}_{S}}{\left(\mathrm{P}-\mathrm{P}_{a}\right.}\right)
\end{array}
$$

Where: $\mathrm{P}$ is the total pressure in the reactor, atm. 


\section{Results and Discussion}

As described before, four desiccants were chosen to carry out the present investigation to study the feasibility and effectiveness of the proposed circulating bed reactor. Eight items were studied for each desiccant for which results showed major compatibility and relatively adjacent behaviours. It was thus decided to discuss the results obtained for one of these desiccants, first, owing to lack of space and, second, to be able to clarify discussion of results without repetition of behaviors related to the desiccant materials. Since silica gel is the material having the widest scope of industrial use of the chosen desiccants, it was chosen to be the representative material for the other three members. Silica gel characterizes also by being of moderate apparent density (0.7), of smaller specific gravity value (2.1-2.3), of intermediate average weight used per unit volume of air $\left(640 \mathrm{~kg} / \mathrm{m}^{3}\right)$, of an accepted value of specific heat $\left(0.22 \mathrm{cal} / \mathrm{g}^{\circ} \mathrm{C}\right)$, of relatively high specific surface area $\left(6 \times 10^{6} \mathrm{~cm}^{2} / \mathrm{g}\right)$ and of average pore diameter of about $4 \times 10^{-7}$ meter which is about 10 times the diameter of the water molecule.

\subsection{Effect of Initial Fines (Fi) Content}

Figure 5 represents the change of the percentage moisture content by time, for percentage fine contents of charges from zero up to $8 \%$. It is clear that an increase in moisture of solids goes on by time and that this increase becomes higher by increasing initial fines content in charges. Also it is clear that the rate of increasing moisture in the circulating solids becomes higher by increasing initial fine content in charges.

These observations, although expected, prove well that the fine content in charges remains unchangeable through out the whole experiment time. Also, these findings are acceptable when considering that increasing fine content increases surface area of solids and thus their ability for moisture adsorption.

\subsection{Effect of Possibility of Fines Loss (F $\ell$ ) From the Bed}

It happens in some chemical engineering processing for solid-gas contacts that the stability of the amount of fines in a bed becomes uncontrollable. This may be due to operating or design variables of the process. This leads to designing some experiments to study the possibility of fines loss if drastic conditions prevail.

Figure 6 presents the experimental findings of the relation of the percentage loss on fines from the charge $(\mathrm{F} \ell)$ against time, for multiples of the minimum fluidization velocity, $\mathrm{U}_{\mathrm{mf}}$, of the charge having the values $6,8,10$ and 12 . This multiple is sympolized $\left(U_{r}\right)$ in the figure and equals, $\left(\mathrm{U}_{\mathrm{f}} / \mathrm{U}_{\mathrm{mf}}\right)$. The initial fine content of the charge was fixed at $10 \%$ of mean particle size of $80 \mu \mathrm{m}$; the particle size of the coarse particles was fixed to $610 \mu \mathrm{m}$ and the ratio of the weight of water, $g_{w}$, to that of solid, $g_{s}$, sympolized as, Wir, was $99.2 \times 10^{-4}$.

The percentage loss of fines increases by increasing $\mathrm{U}_{\mathrm{r}}$, but the loss did not exceed $2 \%$ of the original fines content of the bed which was as high as $10 \%$ of the bed charge. The loss increased from $0.7 \%$ loss for $U_{r}=8$ to $1.7 \%$ loss for $U_{r}=10$, while the increases from $U_{r}$ $=6$ to $U_{r}=8$, or ,from $U_{r}=10$ to $U_{r}=12$ are much less. It was decided thus to use the multiple $U_{r}=8$ for other experimental testings by decreasing also the percent fines in the bed.

To ensure these findings, different particle sizes of the percentage fines were trialed at ambient temperature conditions, $\mathrm{U}_{\mathrm{r}}=8$ and $\mathrm{Fi}$ equals $10 \%$. Figure 7 represents the data obtained which show higher losses for small sizes, and that the range of loss from $0.8 \%$ to 
$1.4 \%$ lies between $80 \mu \mathrm{m}$ and $40 \mu \mathrm{m}$ mean sizes of fines. This gives a proof of the good quality of the separating cyclone used in the design for the compact circulating bed reactor.

\subsection{Humidification and De-Humidification of Air}

Humidification in a circulating bed fluidized by air, means that air is in a nearly dry condition and that the fluidized solid by that air is highly saturated with moisture; the reverse becomes thus the case for dehumidification of air.

Figure 8 represents the case of dehumidification of air where the fluidized solid behaves as an adsorbent. The figure presents data as percent moisture content against time. Solid (silica gel) charge was as dry as it could be, having a moisture content of about $0.02 \%$, fluidized by a nearly saturated air at a value of Ur ranging from 6 to 10 at ambient temperature. The solid charge contains $5 \%$ fines to ensure better fluidizing conditions $[8,13]$.

From this figure it can be seen that the water content of solids increase by time for all tested fluidization rates. After 40 minutes, the maximum attained moistures were between $15 \%$ and $18.3 \%$. The maximum attained after 30 minutes for a value of $\mathrm{U}_{\mathrm{r}}=10$ gave a moisture content of about $23 \%$, then decreased to a lower value of about $18.3 \%$, may be due to loss of fines at that high rate of fluidization.

Figure 9, on the other hand is a humidifying figure, showing curves for Ur values similar to that in Figure 8. The air is nearly dry, while the solid is nearly saturated (about $22 \%$ M.C.). Decrease of solid moisture content, and of course the increase of air moisture content, can be easily detected. The rate of decrease of solid moisture content increases by increasing flow rates of air due to the continual renewal of the dry air stream and thus the very slow decrease in the driving force for mass transfer from the solid to the air phases. 


\subsection{Temperature Testing Trials}

Temperatures of air at 30,40 and $50^{\circ} \mathrm{C}$ in addition to the ambient temperature were used. To test the effect of temperature, a fluidization ratio $U_{r}$ of 8 value was used, the solids were carrying $21 \%$ to $23 \%$ moisture content. As shown in Figure 10, the humidification of air took place at higher rates at ambient temperature. It was surprising to have nearly equivalent results at $50^{\circ} \mathrm{C}$ followed by results at $40^{\circ} \mathrm{C}$ and finally the $30^{\circ} \mathrm{C}$ condition, which was the slowest rate. This may be attributed to some errors in attaining the equilibrium conditions of temperature between air and solids, a speculation which needs further confirmation.

\subsection{A Combined Humidification-Dehumidification Cycle}

Figure 11 shows the results of an experiment carried out by nearly dry solids and saturated air (dehumidification of air cycle), followed by a reverse cycle for the humidification of air; these all were in a lone experiment. The figure shows a normal dehumidification cycle of air, while the humidification cycle shown by a dotted line gives a hysterysis route where the decrease of moisture content of the solids did not attain the original water content, but a higher value. This shown hysterysis may be due to the change of the fine percentage in the charge due to the elongation of the experiment total period of run from 40 minutes to 80 minutes (up cycle + down cycle of moisture content in the charge of solids in the bed).

\subsection{The New Compact Design Against The conventional One}

Figure 12 is a comparative representation between the new proposed compact design (Figure 3 ) and the conventional circulating bed design show in (Figure 4) for attaining the same purpose of drying of solid or humidification of the fluidizing gases (air). The prevailing conditions were the same for both treatments. The results prove that the compact design gives higher value of moisture content to solids for the same processing time periods. On the other hand, the rate of increase of the solid moisture content (and, thus, the rate of dehumidification of air) is higher.

\section{Conclusion}

The newely proposed compact fluidized bed circulation reactor (CCFB), proved its effectiveness and highly accepted performance in drying of solids and humidification of air, as well as dehumidification using solids as adsorbents. It is expected in following trials to test economical rationalization of heat energy. This investigation adds another proof to the previous efforts done to test the feasibility of the new design for pollution control in the combustion of fuels and incineration of solid wastes done in the year 2002 [3]. 


\section{References}

[1] D. Kunii and C. Levenspiel, Fluidization Engineering, john wiley inc., (1969), p.12.

[2] Idem, ibid, p. 354.

[3] M.Z. Abdel wahhab, "Circulating fluidized bed incineration for pollution control", proc. Of first CEE conf., Cairo, Military technical college, May (2002), PP. 261-271.

[4] G.R. Chhatwal and H.C. Mehra. Adsorption and phase Rule, Goel publ. house, 3 rd ed., (1982), p.5.

[5] J.H, ed., Perry, chemical engineer's handbook, 3 rd ed., McGraw Hillbook Co. Inc., pp.880-883.

[6] D. Geldart, powder technology, 7, (1973), pp.285-292.

[7] A. Baeyens and D. Geldart, Toulouse congress proceedings, France, (1973), P. 263.

[8] C.Y. Wen and Y.H. Yu, chem. Eng. Prog. Symp. Ser., 62 (62), (1966), p.100.

[9] E.A. Mahmoud, T. Nakazato and k. kohama, k "hydraulic performance of a circulating powder-particle fluidized bed (CPPFB), $8^{\text {th }}$ china-Japan Symp. On fluidization (CJF8), V.8, (2004), PP. 350-357.

[10] J.k. Vennad. and R.L. street, " Elementay fluid mechanics", $6^{\text {th }}$ ed., John wiley, (1982), pp. 510-513.

[11] W.L. Mc Cabe, J.C. Smith and P. Harriott, "unit operations of chemical engineering", 4 th ed., Mc Graw Hill , (1987), a) P.752, b) P.660 .

[12] K. Kato, T. Takarada, N. Matsuo, T. Suto and N. Nakagawa, "Residence time distribution of fine particles in powder-particle fluidized beds", Int.Chem. Eng., 34, (1994) PP.605-610.

[13] T. Nakazato, J. Li, H. Mitsui, S. Sawaka and k. kato, " Hold-up and agglomeration behaviours of adhesive fine particles in circulating fluidized bed" , proc. Of circulating fluidized bed, VII, J.R. Grace, J.Zhu and H.Lasa, eds, Ontario , Canada, (2002) pp.209216. 

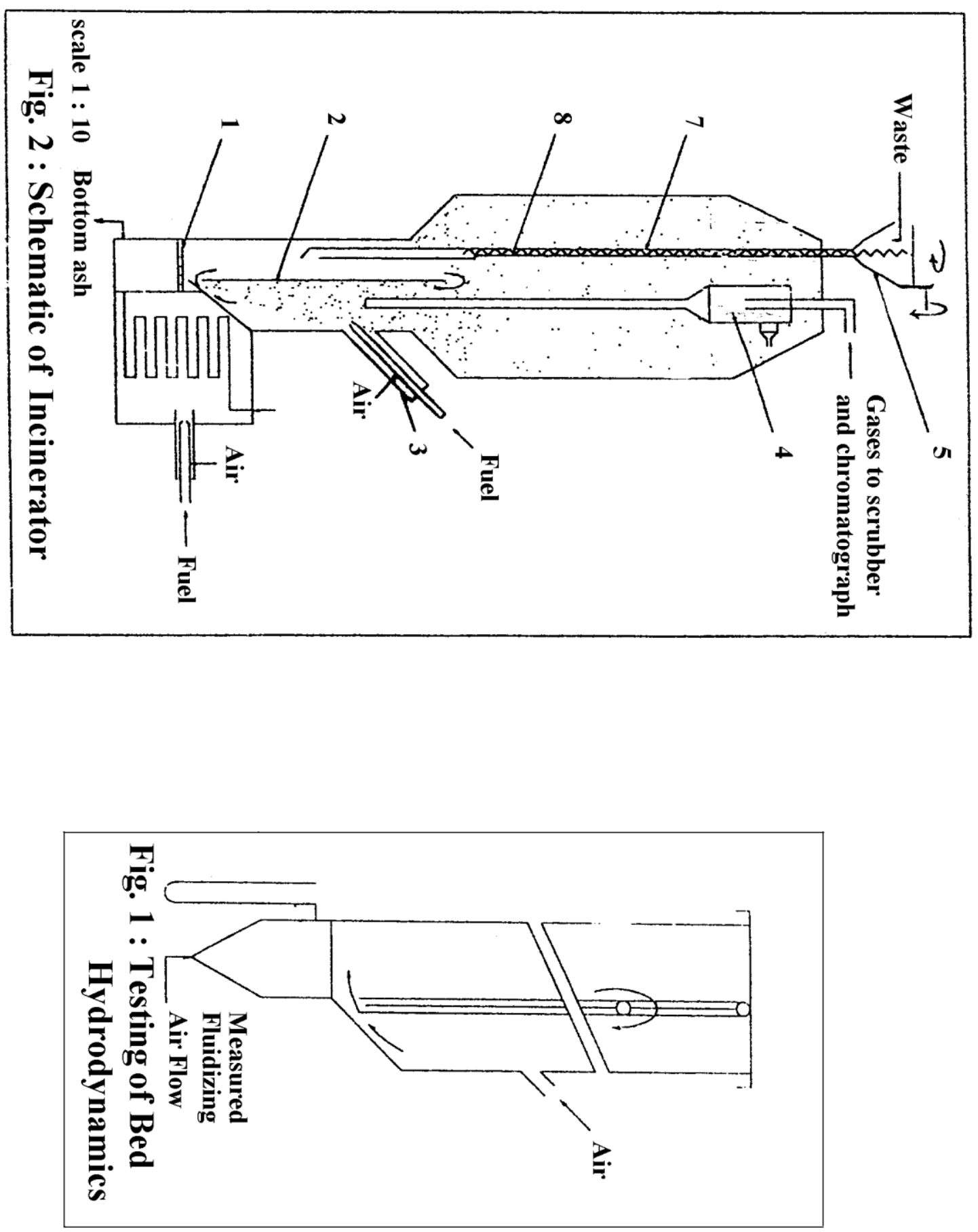


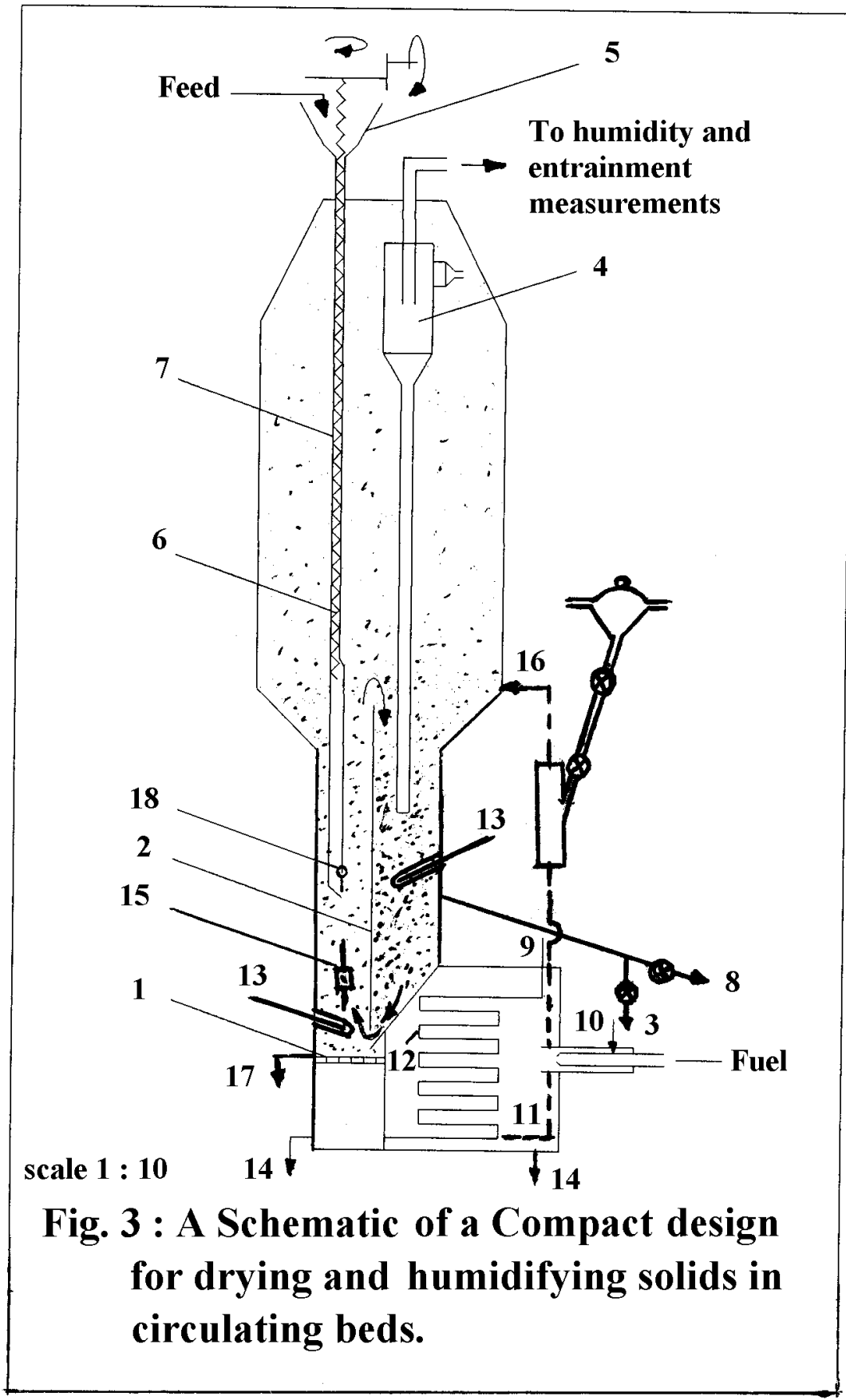

\begin{tabular}{|c|l|c|l|c|l|}
\hline 1 & Air distributer & 7 & Feeding line & 13 & Temperature measurement \\
\hline 2 & Circulating Barrier & 8 & Product exit & 14 & Bottom-ash exit \\
\hline 3 & Sampling line & 9 & Fluidizing air & 15 & Pitot-tube arrangement \\
\hline 4 & Cyclone & 10 & Burner & 16 & Sample return line \\
\hline 5 & Feed Funnel & 11 & Heating chamber & 17 & Solid-batches exit \\
\hline 6 & Screw Feeder & 12 & Air-heating serpentine & 18 & Hinged gate-valve \\
\hline
\end{tabular}




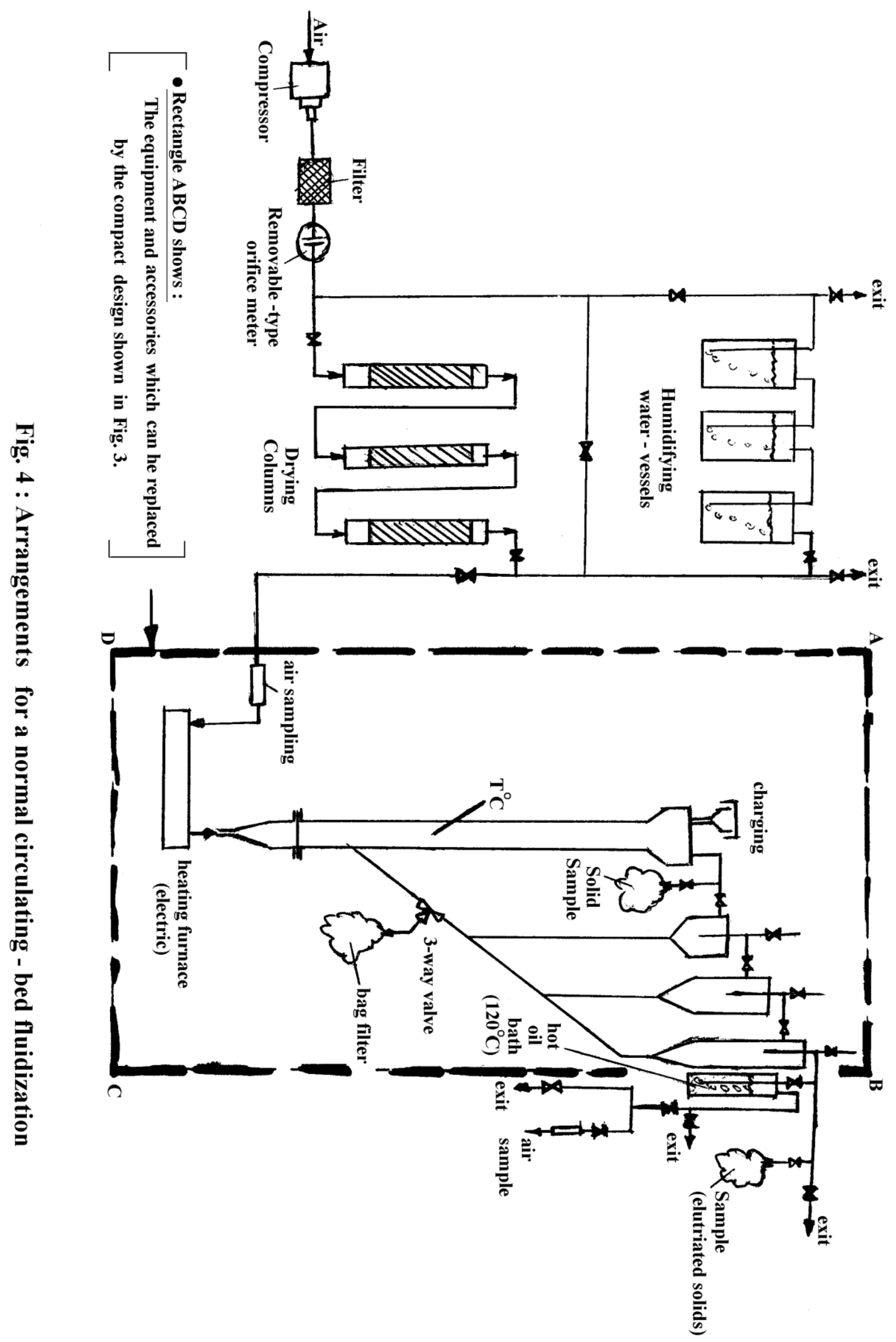




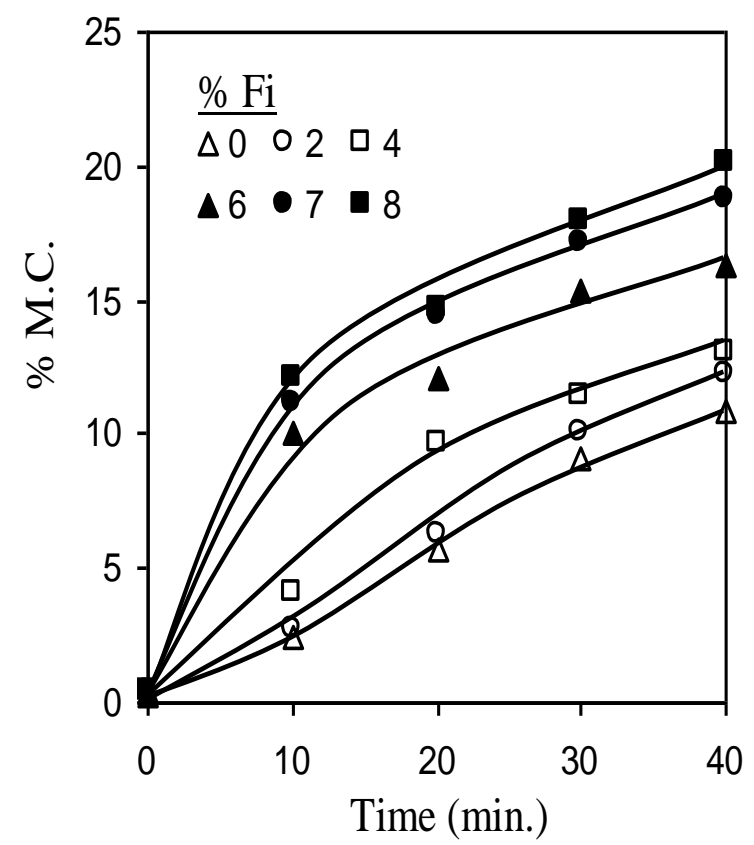

Figure 5: Effect of initial fines content.

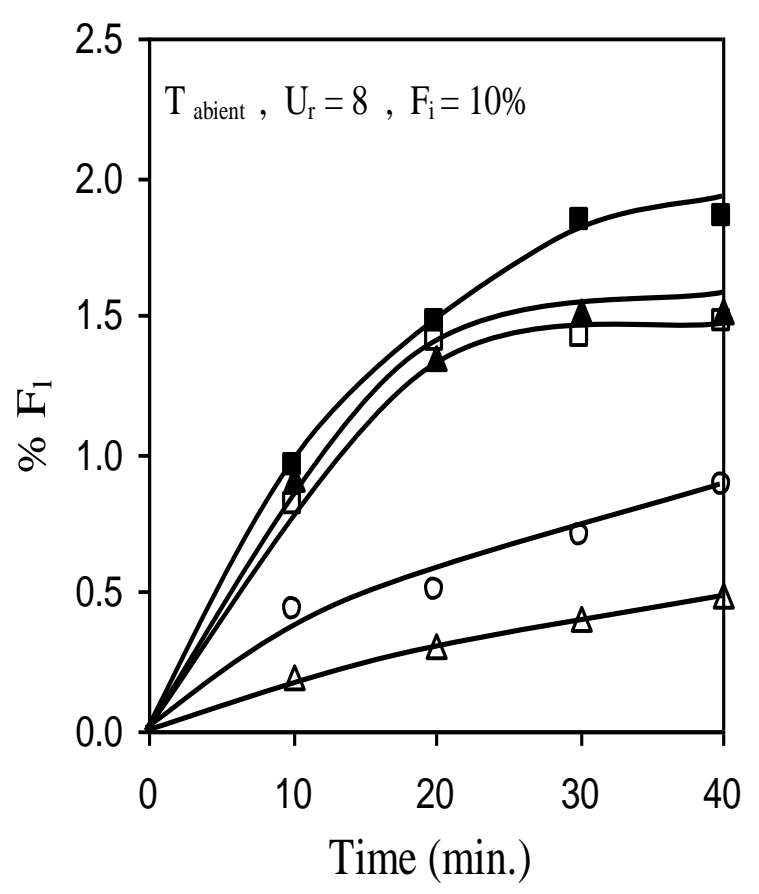

Figure 7: Effect of fine size on percentage fine $\mathrm{d}_{\mathrm{p}}(\mu \mathrm{m}): \Delta 200 \quad \circ 80 \quad \square \quad 40 \quad \Delta 20 \quad \square 10$

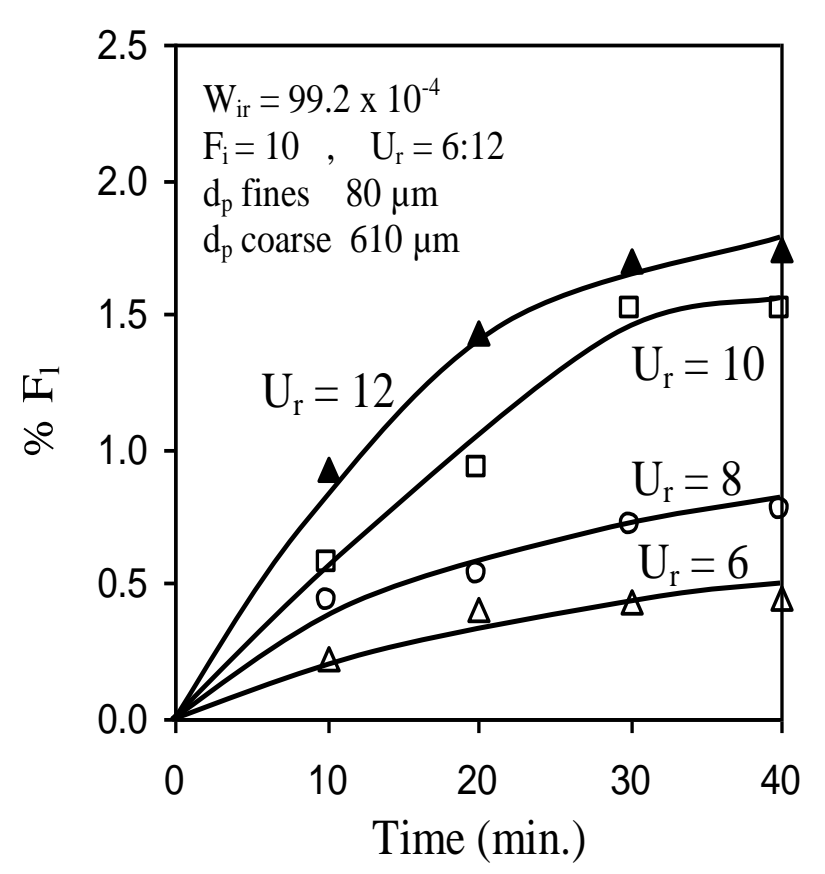

Figure 6: Total fines loss.

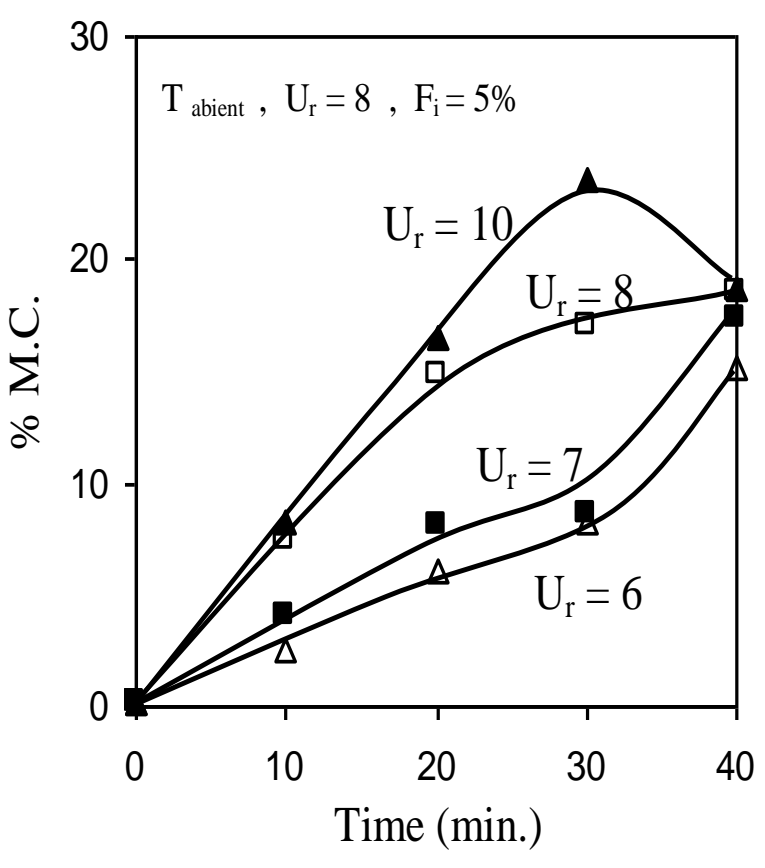

Figure 8: Dehumidification of air. 


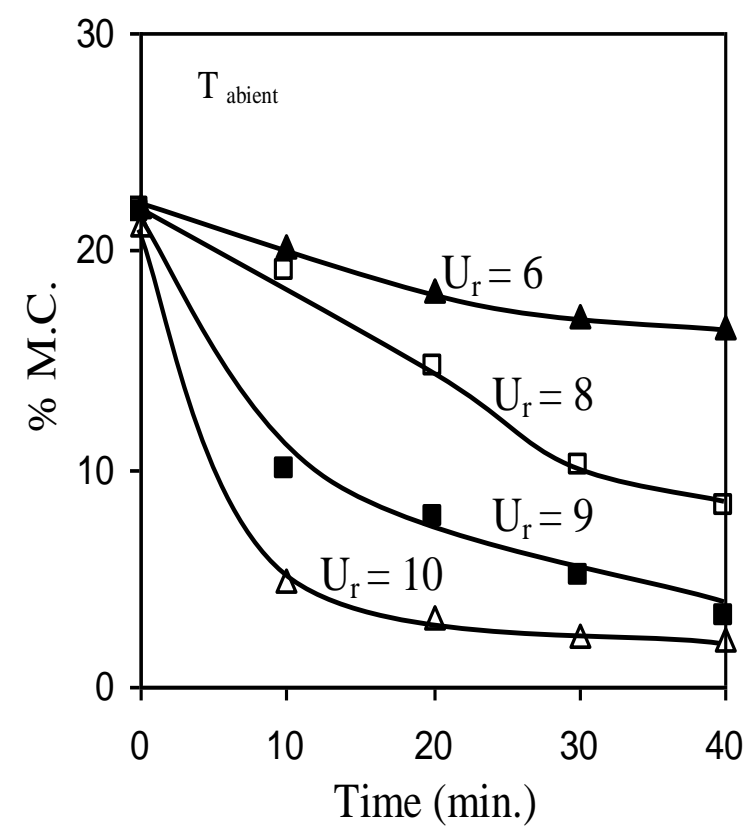

Figure 9: Humidification of air.

Time (min.)

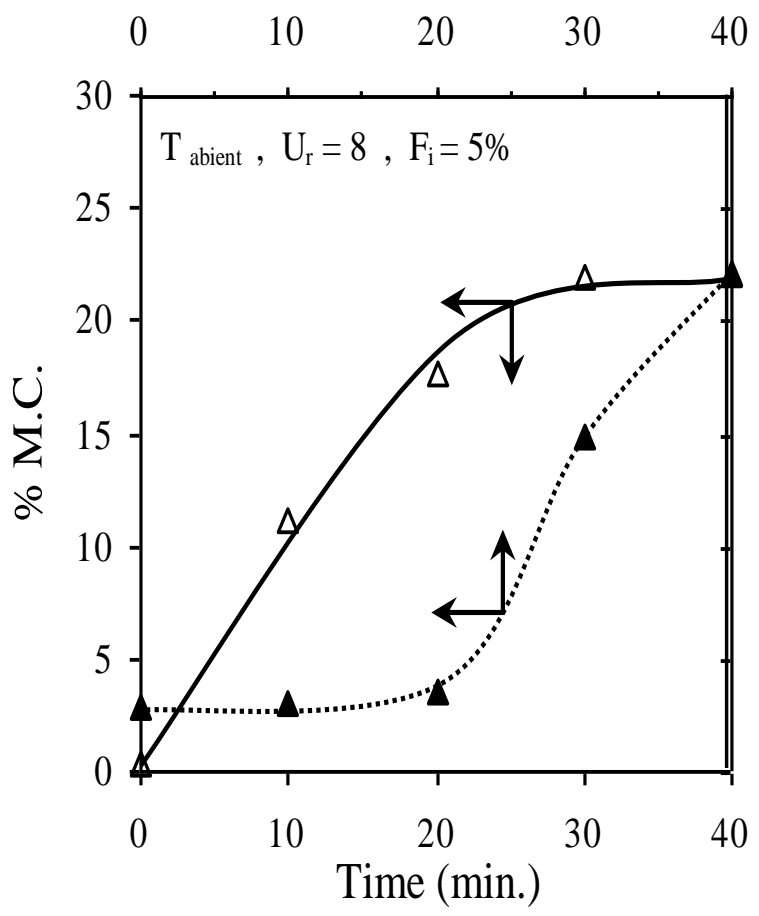

Figure 11: Hysterysis in a combined

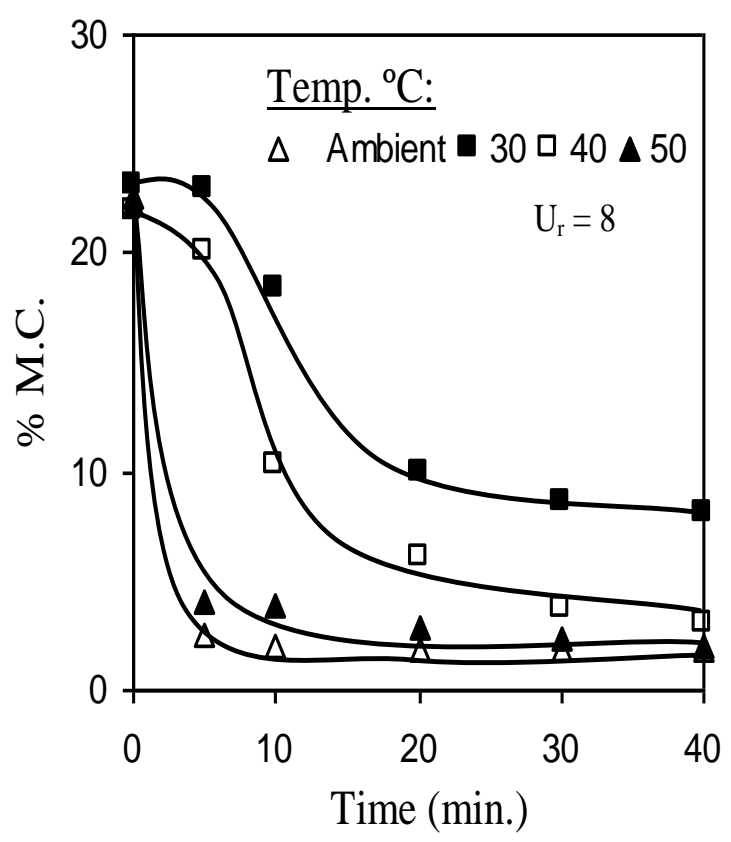

Figure 10: Effect of temperature.

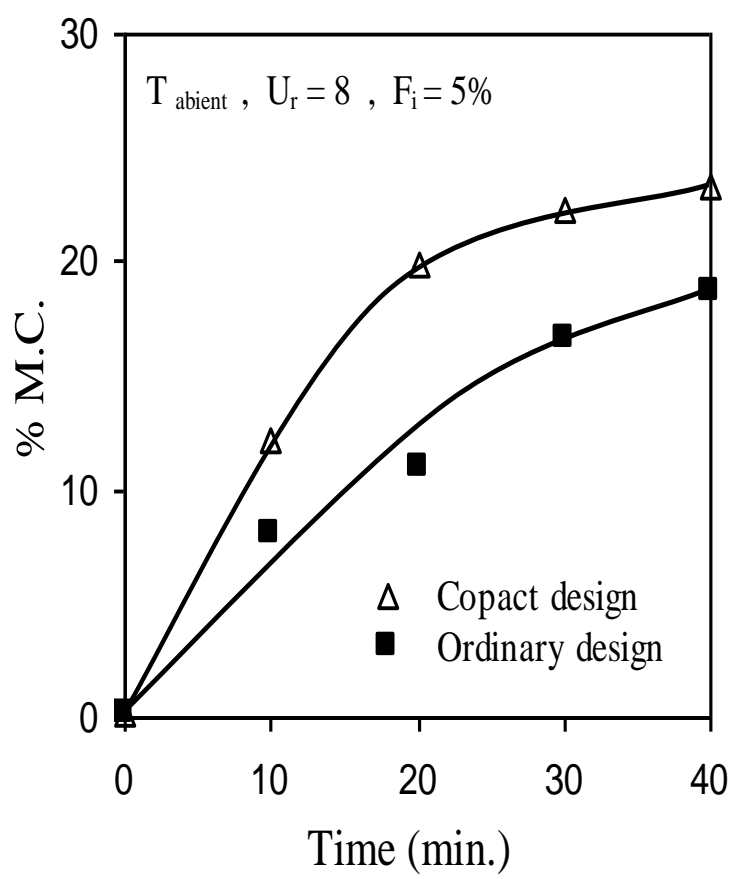

Fig 12: A comparative representation. 
Military Technical College

Kobry El-Kobbah, Cairo, Egypt

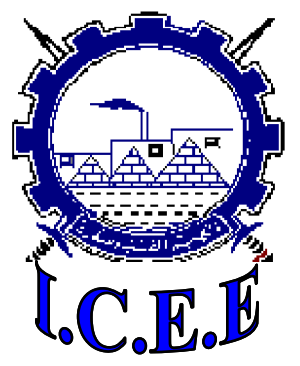

$5^{\text {th }}$ International Conference on

Chemical \& Environmental Engineering 25 - 27 May, 2010. 